\title{
The Prevalence of Cigarette Smoking and Knowledge of Its Health Implications among Adolescents in Owerri, South-Eastern Nigeria
}

\author{
Chikere Ifeanyi Casmir Ebirim ${ }^{*}$, Agwu Nkwa Amadi' ${ }^{1}$, Okwuoma Chi Abanobi ${ }^{1}$, \\ Gabriel Uche Pascal Iloh² \\ ${ }^{1}$ Department of Public Health Technology, Federal University of Technology, Owerri, Nigeria \\ ${ }^{2}$ Department of Family Medicine, Federal Medical Centre, Umuahia, Nigeria \\ Email: ${ }^{*}$ chayke2000@yahoo.com
}

Received 21 April 2014; revised 31 May 2014; accepted 19 June 2014

Copyright (C) 2014 by authors and Scientific Research Publishing Inc.

This work is licensed under the Creative Commons Attribution International License (CC BY). http://creativecommons.org/licenses/by/4.0/

\section{(c) (i) Open Access}

\begin{abstract}
Despite the growing problem of global cigarette use, accurate information on the prevalence and pattern in Nigerian adolescents' remains sparse. The aim of this study was to determine the prevalence of cigarette smoking among in-school male adolescents in Nigerian population and to assess their level of knowledge on the health effects of cigarette smoking. A descriptive cross-sectional study was carried out among 944 randomly selected in-school male adolescents in Owerri, south-east Nigeria, between September and November 2013. Information was obtained using a self-administered questionnaire. The findings indicated a prevalence of $\mathbf{1 5 . 3 \%}$ for ever smoked adolescents and $\mathbf{1 1 . 2 \%}$ for current smokers. The mean age at cigarette smoking initiation was 14 years. Sixty-three percent had good knowledge of health problems associated with cigarette smoking. Lung cancer was the most reported associated health problem. Fifty-two (36.1\%) indicated that they were initiated by their friends who offered them their first stick of cigarette. The major reason for smoking cigarette the first time was to be like their friends/role model and out of curiosity. Poor knowledge of health effects of smoking was statistically associated with cigarette smoking $\left(X^{2}=26.82\right.$, p-value $\left.<0.001\right)$. Knowledge of health problems associated with smoking proved to be the major reason for not smoking by never smoked adolescents, which means that awareness creation on health problems associated with cigarette smoking through health education in schools coupled with stiff legislative ban on sale of cigarette to adolescents will, to a reasonable extent, reduce the high prevalence of adolescent cigarette smoking in our society.
\end{abstract}

\footnotetext{
"Corresponding author.
}

How to cite this paper: Ebirim, C.I.C., Amadi, A.N., Abanobi, O.C. and Iloh, G.U.P. (2014) The Prevalence of Cigarette Smoking and Knowledge of Its Health Implications among Adolescents in Owerri, South-Eastern Nigeria. Health, 6, $1532-1538$. 


\section{Keywords}

\section{Prevalence, Cigarette Smoking, Adolescents, Owerri, South Eastern Nigeria}

\section{Introduction}

Cigarette smoking is the inhalation of smoke from burned dried leaves of the tobacco plant. People may smoke casually for pleasure, habitually to satisfy an addiction to the nicotine present in tobacco and to the act of smoking, or in response to social pressure. Tobacco smoke contains nicotine and harmane, which when combined gives rise to the addictive stimulant and euphoriant properties. The effects of nicotine in beginners or irregular users are increase in alertness and memory, and mild euphoria. Nicotine, however, disturbs metabolism and suppresses appetite [1].

Adolescence here refers to the stage of maturation between childhood and adulthood. The term denotes the period from the beginning of puberty to maturity. It usually starts at about age 11 till 19 yr. The transition to adulthood varies among cultures, but it is generally defined as the time when individuals begin to function independently of their parents [2].

Smoking epidemic has been on the decline in most industrialized countries but in the developing countries data suggests that cigarette smoking is increasing by $3 \%$ per year [3]. It is estimated that the total number of deaths attributable to smoking worldwide will increase from 2.5 million in 1995 to 12 million by the year 2050 [4]. Most of these deaths will occur in the developing countries. Part of the reason is that there are poor public health institutions and there is expansion of tobacco companies into the African markets.

The health consequences of cigarette smoking are slow, gradual, and cumulative. Cigarette smoke is mild enough to be inhaled in overdose quantities. Its addiction has historically been one of the hardest addictions to break. Although the hazards of smoking are well-known, the number of smokers among adolescent students is still high. There are many factors influencing these students to smoking for example socio-economic status, having parents, siblings and friends who smoke, also the social environment around the person [5].

The long-term consequence of cigarette use may be easier for young people to ignore because they feel inherently invulnerable to these far-off risks [6], and many young smokers believe they can quit smoking before the long-term health "bill" comes due for their smoking behavior. However, evidence suggests that most people who begin smoking regularly in adolescence will continue to do so, regardless of their intentions to quit [7].

Smoking prevalence in Nigerian adults (15 years \& older) 1990 National Demographic Health Survey showed that the prevalence rate of smoking in males is much greater when compared to that of females. Males have prevalence rate of 15.4, while that of females was 1.7. Overall: 8.9 [8]. A survey conducted by the United States Centre for Disease Control in Cross River State in Nigeria, found that as many as $45 \%$ of the young people surveyed think boys who smoke and $28 \%$ think girls who smoke have more friends [9]. Again, $17 \%$ think boys who smoke and $16 \%$ think girls who smoke look more attractive. Little wonder, therefore, that as many as $22 \%$ of the sample population currently use tobacco with as many as $20 \%$ of those who had never smoked likely to start smoking in the next year. Young people see their role models like film stars, musicians, and celebrities smoking and portraying smoking as something glamorous. Many also see it as a status symbol, a way of telling your peers and contemporaries that you have come of age.

In Nigeria, there is no age restriction on buying cigarettes. People sell anything to anybody without batting an eyelid. It is interesting to note that most adults prefer to send children to buy cigarettes and alcohol for them. Reference [10] reported a finding of a survey of smoking habits among secondary school children and medical students in Lagos, Nigeria. $40 \%$ of the boys and $8.4 \%$ of girls at secondary school, and $72.4 \%$ and $22.2 \%$ of women at medical school were found to smoke while the habit of smoking of the secondary school boys was influenced by the smoking habits of their parents and friends, the smoking habits of their secondary school girls and female medical students were mainly influenced by that of their friends.

Reducing adolescence smoking rate is essential, since smoking often begins in adolescence. About $90 \%$ of adult smokers start smoking before the age of $20 \mathrm{yr}$ [11]. A good number of these adolescents' are found in the senior secondary school classes and this prompted this study on the prevalence of cigarette smoking among 
in-school adolescents in Owerri, South-Eastern Nigeria. This study explores the present status of cigarette smoking behaviour among in-school adolescents and their knowledge about health risks associated with smoking.

\section{Methodology}

This study employed a descriptive cross-sectional study design, which examined the relationship between smoking status and other variables of interest that may determine smoking initiation.

The study population consists of 16,812 secondary school boys in Owerri. Of these, only those in Class 3 in junior secondary and Class 4-6 in senior secondary were included in the study. This gender was selected because of their higher prevalence from previous studies [12]-[14]. It is also assumed that at this level most of the students who are susceptible to cigarette smoking may have been initiated into the habit as a result of their increased exposure to formal socialization.

This study was carried out in Owerri the capital of Imo state South East Nigeria. Owerri is the capital of Imo State, known as the Eastern Heartland of Nigeria. Imo State has a population of about 3.9 million people and an annual population growth rate of $3 \%$, with a land mass of about 72.5 square kilometers. Owerri has a population density of about 284,981 which predominantly comprises career civil servants, students, professionals, businessmen and semi-skilled workers of mainly Ibo extraction [15]. Owerri has about 40 secondary schools, which comprises of 6 males single school, 6 females single schools, and 28 mixed schools. These 34 schools with male adolescents give a total population of 24,280 students. Total number of boys in secondary school in Owerri sums up about 16,812 students. A sample size of 1000 adolescents was recruited for the study but 944 (response rate of 94.4 percent) complete records were available for analysis.

The instrument used in the collection of data in this study was a self-administered questionnaire. Questions on the questionnaire were based on core survey questions used in all locations [16] as specified by WHO field manual for staff and others questions from past literature reviewed.

The data collected was imputed into the computer for analysis using Statistical Package for Social Sciences version 19.0 for windows. Results were presented in frequency tables and charts. Bivariate analysis was used to investigate association between knowledge and cigarette smoking status. All analysis was done at the $5 \%$ level of significance with p-value $<0.05$ considered statistically significant.

\section{Result}

A total of 944 records of in-school male adolescents in Owerri were available for analysis. The mean age of the adolescents was $16 \pm 2$ years. Majority were in the age group 14 - 16 years (78.8\%), while only $7.4 \%$ were in the age group 17 - 19 years (Figure 1).

\subsection{Prevalence of Cigarette Smoking among Adolescent's}

Out of 944 students, 144 reported that they had smoked cigarette giving a prevalence of 15.3\% (Figure 2). Hundred and six (11.2\%) adolescents were current smokers. The mean age at cigarette smoking initiation was found to $14 \pm 2$ years with majority of the students being initiated within the age range of 10 - 14 years (59.7\%), while $2.8 \%$ were initiated within 16 - 19 years of age.

Documentation of the number of packs smoked showed that $30.6 \%$ of the 144 smokers took less than 5 stick (light smokers), $50 \%$ of them smoked up 5 - 10 sticks (moderate smokers) of cigarette a day, while $15 \%$ smoked more than 10 sticks (heavy smoker) of cigarette. About $43.0 \%$ of the smokers usually smoke in hideouts, $27.8 \%$ reported they usually smoke in at hiding corners in school, $15.3 \%$ indicated they smoke anywhere they wanted to, while $13.9 \%$ said they smoke in their house when their parents/siblings/guardian are not around.

\subsection{Knowledge of Health Problems Associated with Cigarette Smoking among Adolescent's}

Adolescents' knowledge of health effects associated with cigarette smoking showed that 596 (63.1\%) of 944 students had good knowledge while 348 (36.9\%) had poor knowledge of health effects associated with cigarette smoking. Responses to having been educated before in school about the health effects associated with cigarette 


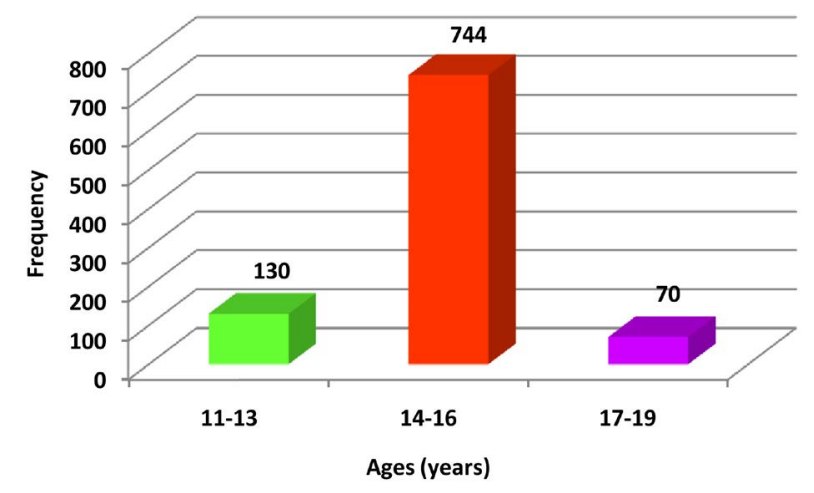

Figure 1. Age distribution of adolescents.

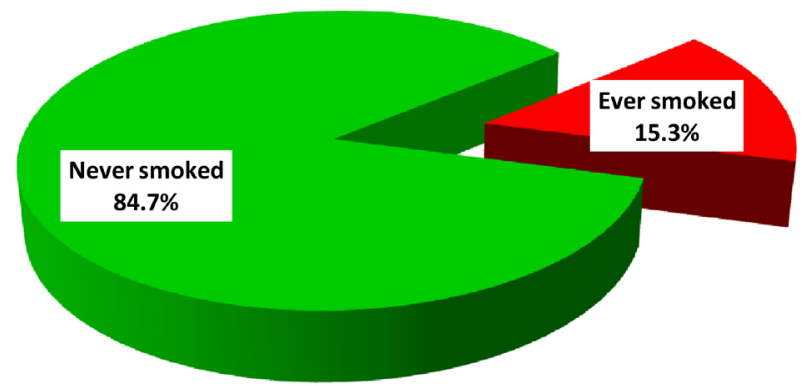

Figure 2. Prevalence of cigarette smoking among adolescents in Owerri.

smoking revealed that 636 students (67.4\%) of 944 had been educated in school while 308 (32.6\%) had not been educated in school about the health effects associated with smoking. Specific effect of cigarette smoking known by the students is shown in Figure 3; 416 (44.1\%) of 944 students reporting lung cancer, 120 (12.7\%) mentioned liver problems, 98 (10.4\%) mentioned heart disease and stroke, 66 (6.9\%) mentioned it causes dryness of skin/lack of stamina/loss of appetite and darkening of lips. Only 5.7\% mentioned mental illness (Figure 3).

Test of association between knowledge of health effect of smoking and smoking status gave a statistically significant relationship, $62.5 \%$ of those that smoked had poor knowledge while $37.5 \%$ of adolescents with good knowledge ever smoked cigarette $\left(X^{2}=26.82\right.$, p-value $\left.<0.001\right)$. This is as shown in Table 1 .

\subsection{Cigarette Smoking Initiation Pattern and Reason for the First Smoke}

Out of 144 students that had ever smoked, 52 (36.1\%) reported they were initiated into cigarette smoking by their friends who offered them their first stick of cigarette. Forty-six (31.9\%) mentioned they were introduced into smoking by a family member who is a smoker. Those that reported they were initiated by their fellow students were 16.1\% (Figure 4). Furthermore, investigation into the main reason for taking first smoke indicated that 56 (38.9\%) of them decided to take their first stick of cigarette simply to be like their friends/relatives/role model. Forty-six (31.9\%) reported it was out of curiosity to taste it while $13.9 \%$ said they were persuaded to take it.

Out of 800, 312 (39.0\%) of respondents gave knowledge health implications as reason for not smoking, 106 $(13 \%)$ reported it is due to advice from parents and society at large while $50(6.3 \%)$ admitted it was due to the cost of cigarette sticks. Out of 106 students that are current smokers, about 62 students were willing to quit smoking of which thirteen (41.9\%) reported that their intent to quit smoking is due to health problems associated with smoking. 20 (32.3\%) reported that intent to quit is due to advice from loved ones, 10 (16.1\%) reported it will be for religious reasons, while 4 (6.5\%) admitted is will be due to the cost implications.

\section{Discussion}

The prevalence of cigarette smoking among the adolescents was found to be $15.3 \%$ for ever smoked while those 


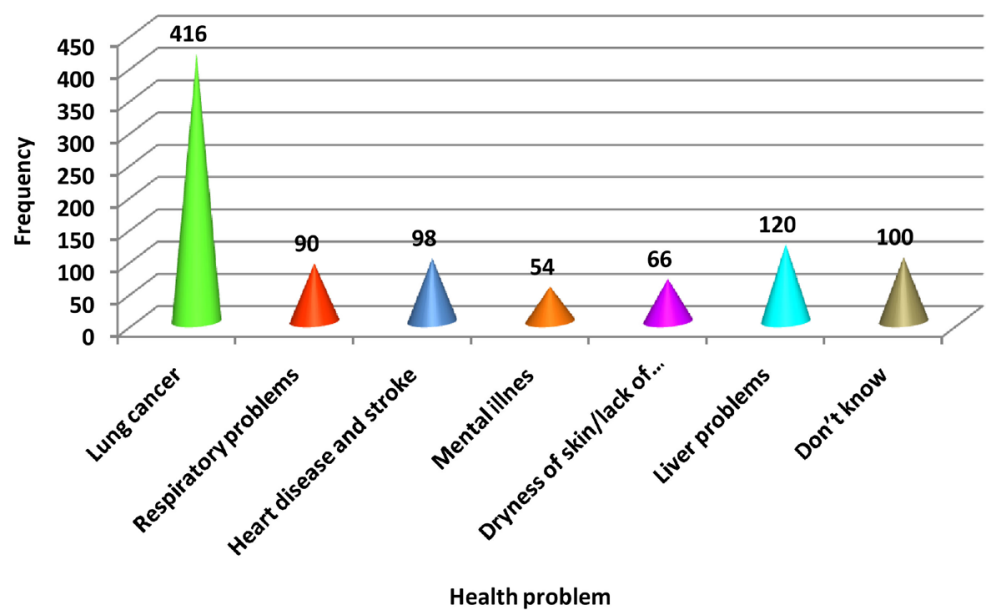

Figure 3. Reported health effects of cigarette smoking by adolescents.

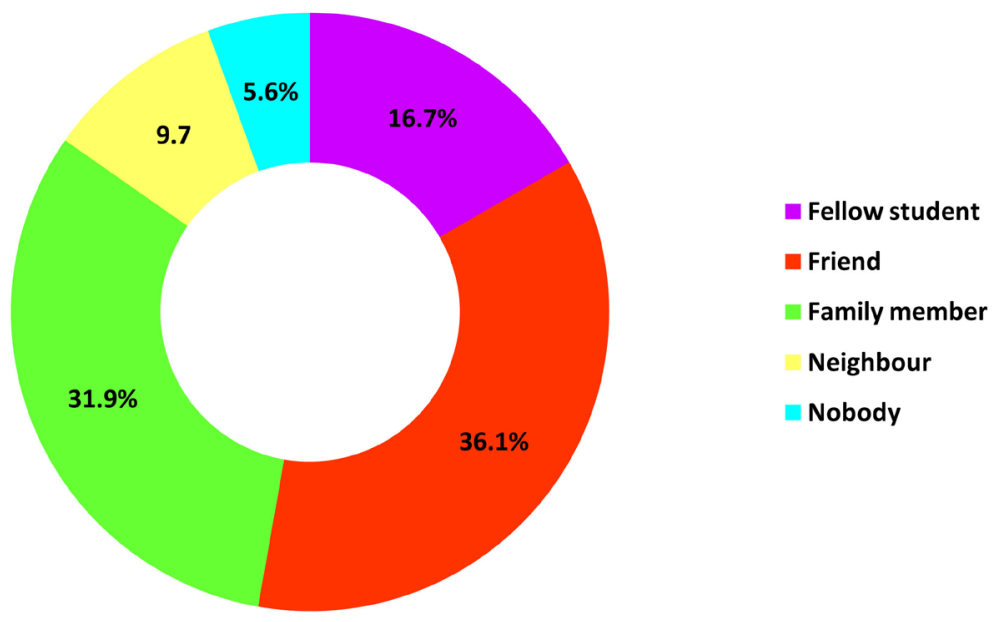

Figure 4. Persons’ influencing adolescents initiation into cigarette smoking.

Table 1. Knowledge of health effects of cigarette smoking by smoking status.

\begin{tabular}{cccccc}
\hline Smoking status & Good knowledge & Poor knowledge & Total & Chi-square & p-value \\
\hline Ever smoked & $54(37.5 \%)$ & $90(62.5 \%)$ & 144 & & \\
Never smoked & $542(67.8 \%)$ & $258(32.3 \%)$ & 800 & & $<0.001$ \\
Total & $596(64.4 \%)$ & $348(36.9 \%)$ & 944 & 23.98 & \\
\hline
\end{tabular}

that of current smokers was $11.2 \%$. The prevalence is quite similar to that reported in 2002 by World Health Organization which gave a prevalence rate of $15.4 \%$ for adults male (15 years and above) in Nigeria [8]. The prevalence was similar to that found by Adeyeye [17] and Odey et al. [18], who reported 16.1\% and 13.0\% respectively for male secondary school students. However, this is higher when compared to that found in Ghana, which reported (12.2\%) for ever smoked and 4.5\% for current smokers [16].

The mean age at cigarette smoking initiation was 14years, this is similar the finding of Adeyeye [17] who reported 12 years. It is also in line with the report of other findings elsewhere in Nigeria as reported by Salawu [19], Bandele [20] and Elegbeleye [10]. This finding might be due to the fact that as boys approaches secondary sexual maturity there is desire to appear mature and take decisions on their own behalf, this can lead adolescents into cigarette smoking. This was similarly reported by Bynner [21] in his study that a desire to appear mature perhaps linked to self-esteem leads to adolescents' recruitment into smoking habit. Also according to Stone and Kristeller [11] about $90 \%$ of the adult smokers start smoking before the age of 20 years. 
Majority of the smokers reported being initiated by their friends who offered them their first stick. This is in line with the report of Adeyeye [17], who reported that the participants smoked their first stick in the company of their friend. This may reflect the inquisitive nature of adolescents which makes them vulnerable to peer group influence. This also reported by Shu Qi [22] and Charlton [23].

This study indicated that majority of $64.5 \%$ were light smokers, the small number of cigarette smoked may be due to lack of boldness to smoke in the open and amount of money available in their pocket. According to Adeyeye [17], the number of sticks smoked may increase over time as they grow older and with independent source of income to fund their habit.

Majority of the students had good knowledge of the various health problems associated with cigarette smoking. This is probably due to the fact that many of them have been educated in school about these harmful effects. Also majority of them knew that lung cancer is associated with cigarette smoking, furthermore, majority of them agreed that cigarette smoking is implicated in heart disease. This showed that the adolescents were conversant with these health problems that result from smoking cigarettes. The health consequences of cigarette smoking proved to be the major reason for not smoking, also current smokers who intended to quit smoking stated health problems associated with smoking to be the major reasons for their intent to quit, this was also found out by Rudatsikira et al., [24] in Addis Ababa Ethiopia he reported that Perception that smoking is harmful was negatively associated with being a smoker.

\section{Limitations}

Although, this study has demonstrated the prevalence of cigarette smoking and its health implications among adolescents, this should be interpreted in the light of some limitations. First, this study was conducted among in-school adolescents, the result may vary with that found among out of school adolescents. Secondly, our results may not be applicable to all in-school adolescent in Nigeria as we only sampled cluster of students in south-eastern region. Thirdly, although, participation is voluntary, we still cannot rule out some selection bias. Nevertheless, our study would serve as benchmark for further studies in other regions of Nigeria.

\section{Conclusion and Recommendation}

There is an increasing prevalence of cigarette smoking among our adolescents. This in future will translate to increased morbidity and mortality if nothing is done to curb the trend. Any intervention made prior to the attainment of 14 years by the adolescence will significantly reduce the prevalence of cigarette smoking in our adolescents. Parents and adults should refrain from smoking in the presence of these adolescents.

Health problems have proved to be a good reason for not smoking by never smoked adolescents which means that health education in schools will to a reasonable extent reduce the prevalence. This should be backed by effective legislation to reduce the trend. Also radio, television and social media should be used to campaign against cigarette smoking in the society. Finally strategies to combat cigarette smoking should incorporate the adolescents themselves, the home, schools and society at large.

\section{References}

[1] Kumari, V. and Peggy, P. (2006) Nicotine Use in Schizophrenia: The Self Medication Hypotheses. Neuroscience \& Biobehavioral Reviews, 29, 1021-1034. http://dx.doi.org/10.1016/j.neubiorev.2005.02.006

[2] World Health Organization (1983) Smoking Control Strategies in Developing Countries. Technical Report Series, WHO, Geneva.

[3] Bartecchi, C.E., Mackenzie, T.D. and Schrier, R.W. (1995) The Global Tobacco Epidemic. Scientific American Journal, 272, 44-51.

[4] Peto, R. (1994) Mortality from Smoking in Developing Countries, 1950-2000. Oxford University Press, Oxford.

[5] Kartasasmita, C.B. (1990) Risk Factors in Smoking Habits of High-School Students. Pediatrica Indonesiana, 30, 31-14.

[6] Gerber and Newman (1989) Smoking, Drinking, and Drug Use in Young Adulthood: The Impact of New Freedom and New Responsibilities, Lawrence Erlbaum Associates, Mahwah, 50.

[7] Gachman, J.G. (1997) Smoking, Drinking, and Drug Use in Young Adulthood: The Impact of New Freedom and New Responsibilities. Lawrence Erlbaum Associates, Mahwah. 
[8] World Health Report (2002) Prevalence of Tobacco Smoking in Nigeria. WHO, Geneva. http://tobacco.who.int/repository/tld100/Nigeria.pdf

[9] Centers for Disease Control and Prevention. Nigeria (2007) Cross River State Global Youth Tobacco Survey. CDC, Atlanta. www.cdc.gov/tobacco/global/gyts/factsheets/pdf_files/nigeria_crs.pdf

[10] Elegbeleye, C. and Femi-Pearse, D. (1978) Incidence and Variables Contributing to the Onset of Cigarette Smoking among Secondary School Children and Medical Students in Lagos Nigeria. British Journal of Preventive and Social Medicine, 30, 66-70.

[11] Stone, S.T. and Kristeller, J.L. (1992) Attitude of Adolescents towards Smoking Cessation. American Journal of Preventive Medicine, 8, 221-225.

[12] Omokhodion, F.O. and Faseru, B.O. (2007) Perception of Cigarette Smoking and Advertisement among Senior Secondary School Students in Ibadan, Southwestern Nigeria. West African Journal of Medicine, 26, 206-209.

[13] Mpabulungi, L. and Muula, A.S. (2004) Tobacco Use among High School Students in Kampala: Questionnaire Study. Croatian Medical Journal, 45, 80-83.

[14] Onadeko, B.O., Awotedu, A.A. and Onadeko, M.O. (1987) Smoking Patterns in Students of Higher Institutions of Learning in Nigeria. African Journal of Medicine \& Medical Sciences, 16, 9-14.

[15] National Population Commission (2007) Official Gazette: Legal Notice on Publication of the Details of the Breakdown of the National and State Provisional Totals 2006 Census. National Population Commission, Lagos, B175-B198.

[16] Ghana GYTS Fact Sheet (2007) Tobacco or Health: A Global Status Report: Ghana. WHO, Geneva. http://www.cdc.gov/Tobacco/global/gyts/GYTS.factsheet.htm

[17] Adeyeye, O.O. (2011) Cigarette Smoking Habits among Senior Secondary Students in Lagos, South West Nigeria. International Journal of Biological and Medical Research, 2, 1047-1050.

[18] Odey, F.A., Okokon, I.B., Ogbeche, J.O., Jombo, G.T. and Ekanem, E.E. (2012) Prevalence of Cigarette Smoking among Adolescents in Calabar City, South-Eastern Nigeria. Journal of Medical Science, 3, 237-242.

[19] Salawu, F.K., Damburam, A., Desalu, A.A., Olokoba, A.B. and Agbo, J. (2011) Cigarette Smoking Habits among Adolescents in Northeast Nigeria. Nigerian Postgraduate Medical Journal, 18, 26-29.

[20] Bandele, E.O. and Osadiaye, J.A. (1990) Variables Contributing to Onset of Cigarette Smoking amongst Young Nigerians. Proceedings of the World Conference on Tobacco and Health, Perth, 1-5 April 1990, 525-528.

[21] Bynner, J.M. (1969) The Young Smoker. Smoking among School Boys. Her Majesty’s Stationery Office, London.

[22] Wang, S.-Q., Yu, J.-J., Zhu, B.-P., Liu, M. and He, G.-Q. (1994) Cigarette Smoking and Its Risk Factor among Senior High School Students in Beijing China. Tobacco Control, 3, 107-114. http://dx.doi.org/10.1136/tc.3.2.107

[23] Charlton, A., Gilles, P. and Frank, L. (1985) Variation between Schools and Regions in Smoking among British School Children. Implication for Health Education. Public Health, 99, 243-252. http://dx.doi.org/10.1016/S0033-3506(85)80028-7

[24] Rudatsikira, E., Abduurahaman, A. and Adamson, S.M. (2007) Prevalence and Determinants of Tobacco Smoking in Addis Ababa, Ethiopia. BMC Public Health Journal, 7, 176. 
Scientific Research Publishing (SCIRP) is one of the largest Open Access journal publishers. It is currently publishing more than 200 open access, online, peer-reviewed journals covering a wide range of academic disciplines. SCIRP serves the worldwide academic communities and contributes to the progress and application of science with its publication.

Other selected journals from SCIRP are listed as below. Submit your manuscript to us via either submit@scirp.org or Online Submission Portal.
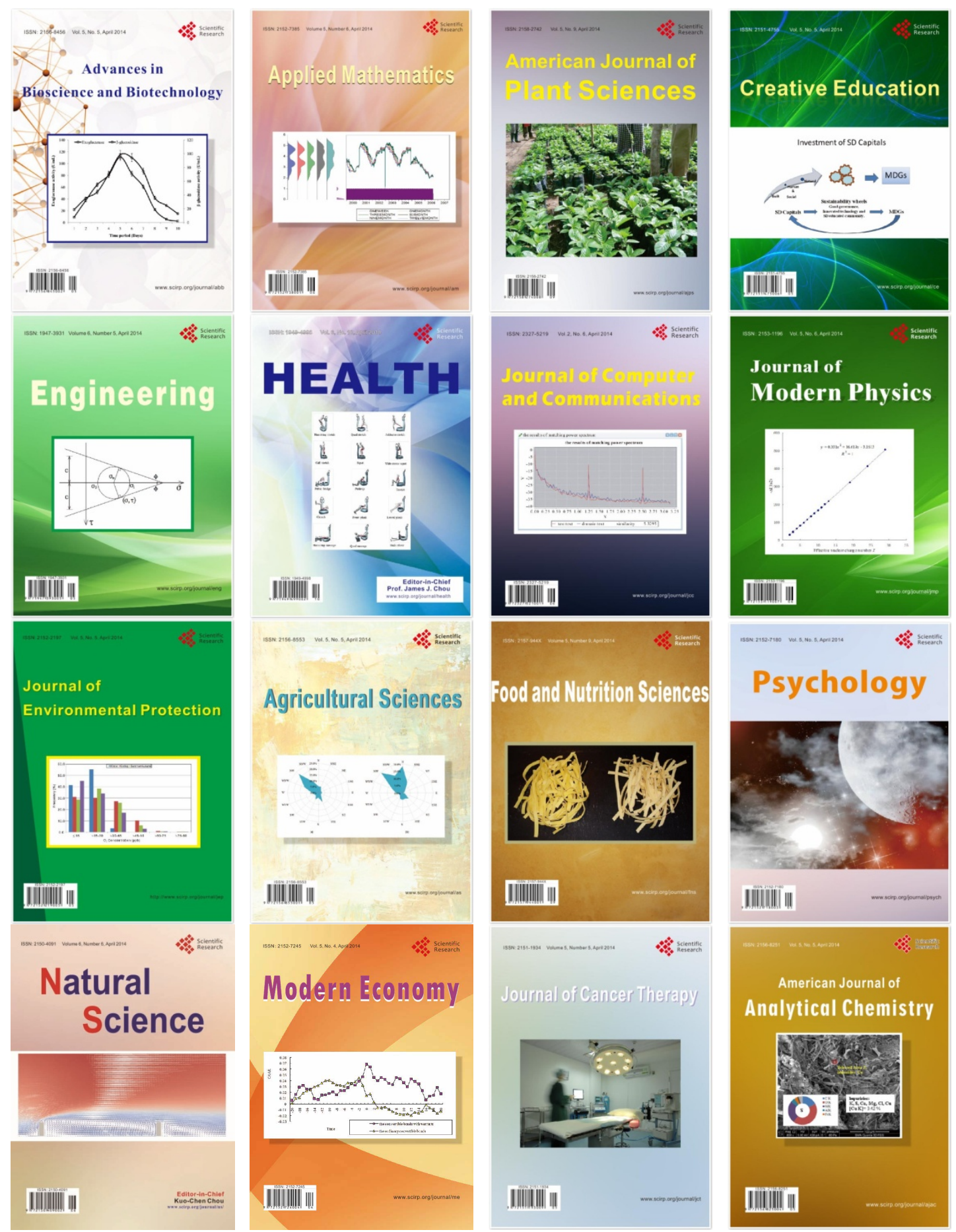